\title{
Challenges, opportunities and legacies: experiencing the internationalising of UK planning curricula across space and time
}

\section{Abstract}

Drawing on interviews with selected UK planning academics and survey results from current planning practitioners, this paper provides valuable and timely perspectives on how internationalisation is experienced by those within and beyond the immediate institutional context. Although internationally focused planning education helps planners tackle the manifold urban challenges in the global South, the paper goes on to argue that relational approaches hold much promise for planners working in so-called developed countries, including the UK, to understand the diverse needs of different diasporic communities. Such knowledge is crucial to develop sustainable planning solutions in the face of uneven processes of urban development.

\section{Introduction}

There has been much discussion over the content of planning curricula in parts of the global North, in particular that more should be done to encourage planners to deliver safer, cleaner, well-designed and sustainable places in range of different geographical contexts (Frank, 2018). Planners, as "world professionals" (Sykes et al., 2015, 82), are therefore being readied to manage the scale and speed of urban growth in parts of the global South (UN Habitat, 2009). But despite these laudable ambitions, there are also repeated concerns over the extent to which planning education in the global North is appropriate for preparing future practitioners to address contemporary and near-future urban challenges (Peel and Frank, 2008; Sykes et al., 2015; Carolini, 2018). There are, of course, several instructive accounts of how global dimensions should be embedded within programme structures (for example, Hoey et al., 2017; Ratnayake and Butt, 2018). However, in response to recent suggestions for more sustained empirical work on the processes surrounding internationalisation, this paper highlights some of the parameters that help or hinder endeavours to internationalise.

Educators are increasingly being called on to address these concerns by weaving different knowledges, epistemologies and practices into planning students' international education 
(Carolini, 2018). And yet, there are also calls for further studies that explore the ways in which planning remains a field suspended between local specificity and universal principles (Frank, 2018, 132). This paper therefore charts the barriers and opportunities associated with incorporating global perspectives - particularly those from parts of the global South into planning education and practice. In so doing, it unpicks the kind of tensions that may threaten bold efforts to innovate and assert continued value to contemporary and nearfuture global urban challenges (Frank, 2018). To this end, this paper uses in-depth interview data taken from thirteen UK planning academics and seventy-two survey responses from planning practitioners to provide valuable insight into the varied challenges associated with internationalisation, as it is being experienced both within and beyond planning curricula. before moving on to discuss respondents' views on recent ideas surrounding the comparative, relational approaches that purportedly offer fresh ways for planners to work through some of the contemporary problems and opportunities experienced in parts of the global South (for example, Roy, 2011; Robinson, 2018). The interview and survey data presented here are then used to examine how planning concepts move in all directions, including from the South to the North. In particular, in developing a more fulsome interpretation of internationalisation, it is argued that tracing the historic connections between and across cities could open-up opportunities for planners both in the global North and the global South to think more seriously about the kind of knowledge and skills diasporic communities might need when developing sustainable planning solution when faced with uneven processes of urban development.

\section{Internationalising planning curricula: challenges and opportunities}

Rapid urban growth in parts of the global South has led to a growing recognition of the need for increased numbers of trained planners to regulate unregulated development, safeguard the health and quality of life of urban populations and protect natural resources (Frank, 2018, 131; see also UN Habitat, 2009). Hence there are repeated calls for planners in the global North to recognise the significance of interactions, flows of people, goods, concepts and differing approaches to planning in an increasingly interconnected, globalised world (Carolini, 2018). A more global perspective, "informed ethics of international practice" (Carolini, 2018, 1), also aligns with broader social sciences critiques around the need to 
decentre the West as being the crucible of urban development and planning thought and practice (for example, Roy, 2011; Robinson, 2018). Increases in global student mobility, the expansion of branch campuses and exchange programmes, together with the transfer of ideas via vibrant international professional networks can all be taken as being positive signs of successful official efforts to internationalise curricula (Altbach and de Wit, 2018, 2). While this may be the case, persistent, lingering doubts remain surrounding whether internationalisation is being sufficiently embedded within planning curricula so as to equip future practitioners with the necessary knowledge and skills to address the complex twentyfirst century challenges of creating high-quality, socially-inclusive and sustainable places (Sykes et al., 2015; Hoey et al., 2017; Carolini, 2018; Frank, 2018).

Of course, debates around internationalisation are set against a backdrop of marketdriven competitive model of education permeating the provision of higher education in the UK. Given recent warnings of the financial challenges facing certain British universities (Augur, 2019), many institutions seek to run courses that would likely attract (premium fee-paying) international students. This in turn raises questions around the kind of socio-cultural and educational factors influencing international students' desire to study in the global North (Waters, 2012; Madge et al., 2015). There are other unresolved issues. These involve the tensions around: balancing the different needs of international and domestic students; managing student expectations of learning localised planning debates deemed appropriate to meet academic and professional requirements; and delivering internationally relevant programmes while aligning with formal quality assurance procedures set-out by the Royal Town Planning Institute (RTPI). As the body overseeing the accreditation of UK planning education, the RTPI has traditionally, though not exclusively, tended to favour a context-specific approach to planning education (Frank, 2018, 139). ${ }^{1}$ Student cohorts can often include a delicate mix of home and international, full-time and part-time, different ages, experiences, backgrounds and expectations. Managing and supporting the "multicultural learning needs" (Frank and

\footnotetext{
${ }^{1}$ All universities offering planning qualifications accredited by the RTPI, at either undergraduate or postgraduate level, must meet required standards for learning and teaching (RTPI, 2012). Accreditation is reviewed and updated, and the RTPI has begun to accredit institutions outside the UK, typically in South Africa.
} 
Peel, 2008, 101) of diverse student cohorts also remains an issue of concern (Haigh, 2014).

Although internationalisation is likely to be shaped by individual approaches to teaching and learning, research agendas and professional capabilities, university support is also needed to foster fruitful cross-cultural exchanges throughout programmes (Haigh, 2014; Craggs, 2019). Of course, different institutions may be better placed to embed and support internationalisation strategies, with curriculum content being drawn from several related disciplines including geography, surveying, architecture, engineering and other built environment subjects. Hence, international approaches may mature at different tempos, motivated by varied ambitions and capacities (Frank and Peel, 2008, 96). Academic skills, language support and willingness or curiosity to learn about or work in different spatial contexts, is similarly important. So, too, is a wider understanding of how students and staff relate to each other both within and outside the formal teaching space-times (Holton and Finn, 2018).

These and other issues are much discussed, of course. Indeed, writing in a US context, Carolini $(2018,4)$ points out that there is a pressing need to learn wider lessons on how planning curricula encourage the emergence of more critically informed practitioners primed to question the internationalisation of planning theory and practice. Elsewhere, in their review of focus data taken from postgraduate students and academics working in a range of built environment disciplines, Frank and Peel $(2008,97)$ suggest that educators are well-placed to highlight some of the pressures involved with adopting and embracing internationalisation in the UK. Likewise, Sykes et al. $(2015,89)$ pose several pertinent questions around how further research should explore how learners and teachers "at the centre of delivering internationalisation" might be made to "work", given the kind of issues and opportunities detailed above. This paper extends these lines of inquiry by focusing on the producers and consumers of UK planning education; it brings together the views of educators and the views of planning practitioners, who have either studied or worked on international planning projects in the UK or elsewhere. Ultimately, therefore, the ambition here is to capture the views of those who have a stake in the design, delivery and experience of planning curricula. In so doing, this paper goes some way to providing a more 
rounded, fuller understanding of how internationalisation is being designed, delivered and experienced in UK planning curricula and practice (Sykes et al., 2015).

\section{Traces beyond the global South}

There is much recent interest in how urban planning models, techniques and their exchanges and adaptations across different contexts (for example, Roy, 2011; Robinson, 2018). And yet, amid the focus on the movement of ideas and policies across space in an era characterised by seemingly untrammelled globalisation, there are also repeated concerns in parts of Anglophone world that the West is not the only point of reference for planners, and that educators and students should listen more to the voices from the beyond the global North (for example, Carolini, 2018). And while there are vibrant international networks that "showcase the diverse tactics" of different international groups, which are sometimes "disregarded by professional [planning] practice" (Carolini, 2018, 4), planners in parts of the global North are being encouraged to embrace a widened "vocabulary of Southern urban practice" (Bhan, 2019, 15), especially when cities and regions are being increasingly interwoven, as they simultaneously "fold-in" and stretch-out across time and space (Simone, 2010; Millington, 2016). Internationalisation in this sense, may be interpreted as forming part of a broader project of public engagement against threats of populism, nationalism and intolerance (Amin, 2019, 7; see also Altbach and de Wit, 2018).

Here, then, is an opportunity to chance to unpick the enduring imprint of imperial governmentality administered by public institutions and private organizations in countries of the global South, and which remain firmly rooted in a specific set of externally transferred concepts (Putri, 2018). A chance, too, to consider and reflect on the forms of tactical, "slumdog" and "unplanned" approaches used by subaltern groups, and how their spatial rights evade, clash or coalesce with the different urban land and regulatory frameworks concerning education, governance, property rights and economic expansion (Roy, 2011). Even so, postcolonial critiques offer potentially new ways to unpick the diverse forms of socalled "pirate modernity" (Sundaram, 2010, 5) used by different groups in the design of selfbuilt housing or to gain access to water, power and other infrastructure networks. 
These are laudable endeavours. But acknowledging historical and contextual factors, including a diverse array of interests, strategies, actions, local coalitions and a range of other human and non-human forces, remain important considerations in the design and delivery of internationalised planning curricula (Porter and Yiftachel, 2019, 178). In the US, for example, Hoey et al. $(2017,224)$ call for planning educators to consider the value of incorporating more deliberative, reflective and contextualised international case studies into existing programmes to foster a "truly" global planning education. In a similar vein, Ratnayake and Butt $(2018,54)$ suggest that broad planning concepts embedded as part of international field courses, often run against students' experiences of local planning languages, historical conventions and administrative structures. The implication here is that "enlightened planners [ought to be] curious to learn from other cultures" (Kunzmann, 2018, 4). Educators and students ought to reflect more seriously on the "suitability and context of transfer" (Ratnayake and Butt, 2018, 53), and the "mercurial" ways in which concepts developed and espoused in the global North translate into practice across space (see also de Satgé and Watson, 2018; Robinson, 2018).

Therefore, unsettled questions remain over how much emphasis planning educators should give to purportedly new ideas around relational, comparative planning, without assessing the merits of these concepts situationally or contextually (Sykes et al., 2015, 84). Indeed, Frank and Peel $(2008,103-104)$ and others recommend that more attention should focus on creating a more locally sensitive approach to the inclusion of international case studies, field visits and experiences into UK planning curricula. Recognising that planning - as the spatial expression of imperial imagination - was often implicated in the projects of Empire-building designed to secure forms of political, social and economic control, might encourage a deeper reflection of why many urban centres across the global North remain home to varied diasporic communities, replete with imperial understandings of ethnicity and power (King, 2009; Roy and Ong, 2011; Jazeel, 2019). And given the extensive international flows and exchanges that have taken place since the nineteenth century (Ward, 1999), such a perspective might push planners to reconsider how planning operates under conditions of globalisation in ways that acknowledge the complex legacies of internationalisation and recognise the hybrid identities these create (Blatman-Thomas and Porter, 2019, 99). This would acknowledge how the legacies of global connection have helped create diverse urban 
and regional spaces, both in the global South and the global North. While there are persistent concerns over funding, resources and service provision, there are connections with recent calls for planners to search for effective ways to communicate with politicians and professionals on the national, city, and neighbourhood level (Jackson et al., 2018). Although planning for multicultural cities is well-covered ground, Sandercock, for example, suggests that further work lies ahead for planners to engage with the diverse "pasts of communities" in ways that will help to help build sustainability, governance, health and well-being (Sandercock and Piazzoni, 2017, 283-284).

\section{Methods}

The data we are using in this paper has been collected within one of the strands of a wider UKRI collaborative project on Higher Education in South Africa, developed in close partnership with two planning accreditation bodies, South Africa Council for Planners (SACPLAN) in South Africa and the RTPI in the UK. While having a key focus on South Africa, this project also explored the implications of internationalising UK undergraduate and postgraduate planning curricula and the wider challenges encountered by planning educators and practitioners as they experience internationalisation. In so doing, it extends recent suggestions for more attention to be directed to the experiential aspects of international planning (Sykes et al., 2015, 82).

To do so, first, detailed interviews were conducted with planning educators teaching on RTPI-accredited planning courses in the UK. However, to generate a range of views on some of embedding internationalisation in UK planning curricula, this study deliberately sought the views of those respondents working at universities that face different educational, institutional and professional challenges. To this end, therefore, thirteen interviewees (eleven males, two females) were consulted. Seven of which were drawn from a selection of "Russell Group" universities, three interviewees came from former university colleges, and three from "new" universities. Participants were deliberately selected with a range of 
teaching experience across undergraduate and postgraduate planning programmes. ${ }^{2}$ Some respondents held entry-level permanent academic positions, while others held senior, professorial posts.

Ultimately, this provided valuable perspectives on different approaches to teaching and research in an international context. The courses also varied in size and composition, thus giving the researchers useful data on programmes which reflect the different "rhythms" of internationalisation (cf. Frank and Peel, 2008). For example, those programmes located in universities located in large urban areas have a large and increasing number of international students, especially from China, parts of south-east Asia and other former British colonies. In other planning schools, though, the ambition to embed internationalisation is not so keenly felt, and hence the courses tended to recruit fewer international students. During the interviews, participants were asked about their feelings towards internationalisation, their thoughts about the extent to which international theories and concepts had been successfully woven into planning syllabi, and whether programmes fully reflected "global shifts in scholarship and practice" (Carolini, 2018, 2). Each interview lasted between 30 and 45 minutes; the discussions were recorded and transcribed for analysis in NVivo. Following the building of inductive codes, an iterative process of re-reading transcripts was used to build themes and codes, which were then confirmed by the research team.

Second, an online survey was conducted to capture the views of current practicing UK planners. The RTPI distributed the survey in its February 2018 "Members' Bulletin”. Survey respondents were asked to provide fulsome responses to open-ended questions about their time working in planning, their thoughts regarding the value of international planning education, whether they have worked in international contexts, and their perspective on the kind of experience needed to work in different international contexts. Demographic

\footnotetext{
2 "Russell Group" universities refer to the "leading" twenty-four public research universities in the United Kingdom. Historically, the term university college was used to denote colleges that delivered university-level teaching; many went on to achieve university statuses during the twentieth century. "New" universities emerged following the enactment of the UK Government's Further and Higher Education Act 1992, when former polytechnics and some other institutions were designated as universities in 1992-1993.
} 
data were also collected from participants. Seventy-two responses were received. Of these, twenty-eight respondents gave detailed answers to all questions posed; twenty-one individuals self-identified as being "White-British" and seven identified with a "White Other" group. These data go some way towards responding to recent suggestion from Ratnayakee and Butt (2018) and others that more evidence is needed about whether planning programmes are supporting students to deepen their knowledge of international planning debates. But rather than focusing on the perspectives of current or recently qualified planners (cf. Ratnayakee and Butt, 2018), the survey also captured the perspectives of practitioners with a range of post-qualification experience, from newly-qualified to those with considerable experience of planning practice. This provided the researchers with a small, but highly-valuable, cross-section of practicing planners' views on internationalisation. In particular, the following narratives provide timely insight into how comparative, relational planning approaches are finding expression in UK planning curricula. This considers the wider institutional and teaching contexts in which internationalisation takes place, while also highlighting the views of educators and practitioners towards developing a more sophisticated, international understanding of planning.

\section{Experiencing internationalisation}

Most interviewees spoke warmly about the broad ideas surrounding ambitions to internationalise UK planning education. Respondents were generally positive about the recent efforts to explore the global nature of planning. Indeed, for some, embracing new knowledge and skills would likely enrich curricula, attract diverse student cohorts, while encouraging students to reflect more deeply on the value that broader international perspectives might bring, particularly in tackling the impacts of climate change, urban growth and other global challenges (Carolini, 2018; Frank, 2018). International field scholarships, case studies, field visits, exchange programmes, innovative modules, and research opportunities were often highlighted through the practitioner survey and the interviews as examples of where internationalisation is integrated in a sustained and positive way. Some interviewees also welcomed the chance to draw more on non-Western knowledge bases, make more use of the expertise of internationally-minded educators, and argued that additional institutional support would embolden staff to "broaden their 
knowledge and experience of international planning debates" (R11, male, Russell group university). In this sense, internationalisation woven into planning curricula can act as an important way to bring people, places and scales together in ways that may facilitate potentially innovative, exciting cosmopolitan exchanges (Amin, 2019).

While respondents would repeatedly highlight that efforts to internationalisation are often buoyed by good intentions, other participants provided some rather unvarnished views on the managerialist approaches used implement and manage the process of internationalisation. Echoing the widely-rehearsed concerns regarding the role and purpose of higher education at a time of financial uncertainty and continued pressures to attract new sources of income (cf. Knight and de Wit, 2018), interviewees often spoke candidly of the institutional ambitions to boost student recruitment for economic and political purposes. And certain universities may have a particularly strong drive to internationalise; other institutions, however, may be reluctant, unwilling or simply unable to develop and market more internationally focused planning programmes. Nevertheless, there was a strong sense among some interviewees that a push towards international student recruitment has rather skewed the educational priorities of some planning programmes, leading to fears around disciplinary fragmentation and the "knock-on effects" caused by "internationalising the curriculum" (R5, male, Russell Group university). One interviewee highlighted the kind of tensions involved with universities seeking to differentiate themselves in a competitive, global marketplace, while delivering high-quality, geographically focused and professionally accredited education:

Like so many universities have agents all around the world trying to recruit students and staff go out and do visits and so on and so forth. I think [international students] come to the UK, and [UK universities] benefit from that because the reputation of higher education and accreditation is very strong. [But this is] driven as much by the centre of the University and sort of strategic relationships at a high-level [and] then it was left to schools to work up the detail (R2, male, Russell Group university).

Moreover, there are very tangible concerns around the practicalities of delivering a more contextualised planning curricula that embrace intellectual contributions from beyond the 
Anglophone academic tradition. Delivery is often mediated by a seemingly uncontrollable blend of individual life-worlds, academic skills, personal motivations, professional contexts, teaching and research interests, and professional capabilities (Frank and Peel, 2008, 105; see also Craggs, 2019). And while there may be very earnest attempts to weave internationalisation into institutional and course space-times, the experience of international planning education, does not necessarily follow "scripted" policies or practices. Or, as one interviewee suggested:

So [internationalisation] is varied, I wouldn't say there's a global coverage of it all. So, it gets back to individual philosophy, individual lecturer, to that philosophy, is it something they want to promote in teaching and research, and so on. If your teaching philosophy does not encompass that internationalisation agenda, then of course it won't [deliver wider goals]. It needs to be collective across the discipline and professionally (R8, male, former university college).

There were other related concerns over how best to think critically about the competing claims to space, and the kind of outcomes that shape the quality, form and identity of place, without having a full awareness of the "compositional requirements of students" (R10, male, Russell Group university). Appreciation of the rich mix of identities, abilities, learning styles, language levels, language requirements, cultural backgrounds, expectations, motivations and prior experiences, is clearly important. For some, finding ways to accommodate and celebrate such diversity, allowing for "much stronger class and course contributions" (R4, female, "new" university), is sometimes difficult, especially for those more internationally focused programmes (R3, male, Russell Group university).

Unsurprisingly, perhaps, interviewees suggested that improvements might be made to ensure that language used by educators in the learning environment equates to the language requirements of the students (R3, male, Russell Group university). And there were other messages regarding institutional support and staff development needed to deliver a more outwardly facing, though ostensibly UK-based curricula. Clearly, certain institutions are seen as being particularly attractive to international students; marketing, recruitment 
and support strategies around academic and language skills are in place to assist internationally diverse cohorts:

What we have tended to do beyond the class, that is not so much the mainstream content changing but it's been about support mechanisms to overseas students with extra kinds of drop-in sessions, advice on study skills, writing essays, English language and various other human skills. Things that are, in a sense, on top of the normal two-hour lecture and one-hour seminar that happens in a week on each module (R9, male, Russell Group university).

Still, there are lessons here for those universities keen to deepen the internationalisation of their planning programmes. For some interviewees, bold and often well-intentioned ideas around embedding internationalisation are at risk of being interpreted as being an unnecessary burden on the time, energy and resources of hard-pressed staff (Madge et al., 2015). As the following interviewee suggested, some may hesitate at devoting substantial effort to "making internationalisation work" (Sykes et al., 2015, 86) when faced with other competing teaching and research demands:

We sometimes feel a bit powerless [...] I think, to support students in the way that we might want to. My personal instinct would be that it's an area where the university could do more and I think as it now starts to become more internationally active and aware over the last few years (R1, male, "new" university).

Likewise, at the micro-level of individual modules, there are challenges surrounding how "best" to manage the circulation of different international knowledges within student cohorts (Madge et al., 2015, 681). One interviewee suggested that there are underexplored issues around the way that student friendships form and interact in time-spaces both within and beyond the university setting (Holton and Finn, 2018, 438). While this can often help build cultural solidarity, companionship and identity, it can lead to a "splintered", partial and insular experience of planning education. There is a danger, therefore, that potentially valuable student insight of the planning challenges experienced in different parts of the world may remain hidden because of these classroom dynamics: 
One group of international students felt that their international experience was very dominated by the presence of another large cohort of other international students, which is odd. They're not British students saying that, but other students from elsewhere who are feeling that they've come to a place where it's very much focused on one other international group, which had sort of bound together. So, this is a real challenge to get right, the balance (R5, male, Russell Group university).

Overall, though, open and diverse learning environments, where rich debates and creative planning emerge, were often welcomed by interviewees. International case studies, welldesigned UK-based or international field visits, and international exchange opportunities were often mentioned in this context. That said, while home-based or overseas field-based approaches are often attractive to both UK and non-UK students, they also have financial, environmental, time and resource implications. For example, they may also restrict the diversity of international planning issues that can be covered during the time-bound visit. And, invariably, they may form a relatively small component of UK planning courses. Nevertheless, as Hoey et al. $(2017,225,231)$ acknowledge, developing "immersive" ways to expose students to dynamic global debates surrounding infrastructure planning, disaster management, planning for urban expansion, and other relevant topics, will better prepare tomorrow's planning professionals. For one interviewee, placing students in safe but unfamiliar surroundings, replete with different cultural customs, sights, smells and sounds, encourages tolerance, adaptability and a willingness to live (albeit temporarily) and work in potentially challenging contexts. In turn, this may strengthen students' ability to learn, act and plan:

Because yes, [good] language skills are one thing, but it's not the only thing. So when I take students on overseas field visits they also learn how to, you know, how to approach people, talk to people, they learn how to, in our case you know very well, but learning how to not be, how to be a little more open, how to, you know, move around, smile, touch, smell, see and things like that. So, it's not, so being a planner is not just about [laughs] knowing how to develop policy or apply a policy or something like that, it's much more than that. And if our home students here, the UK students, move to other contexts, they will have to learn all that as well (R4, female, "new" university). 


\section{Go South, but remember, context is key}

Interviewees spoke warmly of how internationalisation offers an opportunity for planning curricula to consider a wider set of theories and practical examples from beyond standard interpretations of western-dominated urbanism. And this resonates with wider notions of creating more expansive global perspectives that might offset historically rooted anxieties circulating among those seeking to protect national identities and create bulwarks against international mobility, transnationalism and cosmopolitanism (Amin, 2019, 4-5). Indeed, both the survey respondents and interviewees talked of the need for relevant, diverse knowledge bases that reflect much-discussed social science ideas around the interconnectedness of place. The implication being that such thinking creates new opportunities around how best to understand the commonalities, continuities in the urban process in different socio-political contexts stretched across the world (Robinson, 2018). Here, for example, there was a feeling that there was sufficient discretion in the curriculum to allow space for more comparative thinking, which, in turn, opens-up potentially rich areas for research and teaching:

There is considerable discretion to schools in the way that they construct courses, but obviously it's important that the curriculum works ... [Nevertheless], you can equally teach spatial planning knowledge within the context of a comparative framework and it's that overarching comparative approach which looks at planning as a global activity (R10, male, Russell Group university).

In this sense, being alert to how (spatial) planning transfers and adapts in different societies could form part of a more "universalist" planning education (Sykes et al., 2015). But there are other benefits here. For example, such an approach also provides an important set of skills needed for students to access the global labour market:

I would go for that more holistic view of making sure our students are, I think the word globalised, or aware of practise, you know, from a planning point of view, particularly practises and research growing throughout the world. So, particularly planetary urbanisation, 
where the job opportunities for them are actually across the world (R3, male, Russell Group university).

I don't see any more that we're dealing with, in quotes, single uniform groups of planners; and assumptions about what people need in one country or another country could be fraught with some difficulty. It's about the context and what actually makes up that context [...] How knowledge and skills are then applied for good into international contexts [...] ideas change, of course, but I think increasingly attention needs to be paid to the lifelong learning aspect of planners (R13, male, former university college).

Although most respondents welcomed the idea of developing shared planning knowledge and delivering professional learning 'in and for all nations' (Sykes et al., 2015, 84), there were concerns from interviewees over the need to retain a sense of perspective. For instance, not all planning students aspire to think in broader terms, either. A focus on the local scale remains an important consideration, especially given that both UK and non-UK students will likely have to wrestle with ostensibly local issues during their professional careers. Hence the need for a planning education to retain a solid grounding in the specific frameworks, and how to communicate with citizens, developers, politicians and powerful stakeholders in urban development (Kunzmann, 2019, 6). While planning education is being shaped and informed by a seemingly increasing number of interdisciplinary perspectives around the different role of urban planning under conditions of globalisation (Frank, 2018, 139). However, efforts to broaden the educational underpinnings can sometimes jar with official UK-centred accreditation processes, quality assurances and the needs of UK employers:

[Planning] is such a wide-ranging discipline; it becomes quite problematic in terms of training individuals to deal with the range of organisations and the range of activities involved in a degree programme. So, I think that tension between training and education has always been there. It's probably getting worse because as we internationalise, we probably spend even less time looking at the minutia (R7, male, Russell Group university).

Some international students don't really mind the UK-focused curricula; yes, much of it is about the British system, but their main aim is to get a British planning degree. And they 
wouldn't particularly thank you if you started trying to teach some other stuff (R12, male, "new" university).

In this sense, respondents' narratives tended to highlight the tensions between the internationalisation of the educational landscape and some universities' traditional focus of attracting UK students, while delivering planning curricula that reflect local and regional links (Frank, 2018, 132). Interviewees also remarked that it was sometimes difficult for planning curricula to strike an appropriate balance between embedding recent international case studies alongside professional, institutional and practical requirements (cf. Carolini, 2018). Nonetheless, some experienced planning practitioners pointed to how planning education should also encourage and bolster a sense of acquisitiveness; a willingness to listen and learn from "elsewhere":

Curiosity. Openness, listening and observing a lot before speaking. Understanding planning as a way of managing people in space here and now - but that it is subject to change - not as an absolute recipe [...] adaptability [is important] (female, twenty years' planning experience).

Willingness to at least attempt the language is important for planners; grasp of / interest in history [...] willingness to listen a lot before pontificating (male, fifty-two years' planning experience).

Learning is a two-way process. British planning has a long and valued tradition, but it is not God's gift to the rest of the world. Active involvement with outside bodies; not merely confine oneself to the academic institute in which involved - other clubs, groups and societies (male, fifty years' planning experience).

Other practising planners, especially those with less than ten years' professional experience, similarly suggested that planning curricula could do more to encourage students to bolster their knowledge of different national, local, socio-cultural, and political contexts. For some, therefore, these skills represented "gaps" in current planning education provision, and seen as being important to those future planners wishing to build a successful career beyond the UK: 
It's important to learn about influences of systems and culture on urban development (female, aged 18-24, one year of planning experience).

More basic knowledge of how planning systems differ in each country (female, aged 25-34, three years' planning experience).

Understanding different planning systems; understanding different political climates (male, aged 24-34, five years' planning experience).

It would be useful to learn more about other planning systems at university (male, aged 25-34, six years' planning experience).

Overall, there was a sense that internationalised planning education can play an important role in creating "creative, analytical thinkers" (R3, male, Russell Group university); openminded students and practitioners that can draw on international experiences and contemporary case studies to deliver safer, well-designed, sustainable places of the future. But there were other tensions here around whether more might be made of the practicebased strategies emerging from practitioners, advocates, and scholars in the global South (Carolini, 2018). For example, some interviewees recognised that there was "more work to do to ground debates about postcolonial urbanism into concrete reflection about how this changes the way we teach" (R6, female, Russell Group university). For example, seeing and interpreting the world as being increasingly interconnected does not automatically "explain away" the functioning of economies, culture, or the other internal and external forces that impinge on indigenous contemporary planning processes (cf. de Satgé and Watson, 2018; Ratnayake and Butt, 2018; Robinson, 2018). Echoing Peel and Frank's $(2008,94)$ point that internationalisation offers the potential to respect the history, traditions and values of particular geographical contexts, certain respondents cautioned against jettisoning established ideas about the historical processes and actors involved with the planning and management of places:

But it's not just what geographers might call policy motilities [...] the currents of planning history move in all directions, too, [and] there are examples of transmissions all over the world [...]. And the more international, the more essential it is to understand the background 
and intellectual history of thinking about the environment, cities, resources and property challenges (R10, male, Russell Group university).

Understanding the legislatives and policy regime of foreign countries is important; the policy objectives, and how they apply locally. This is transferable from UK work experience, but only to a limited extent, without understanding how they translate and adapt (Male, White-British, aged 25-34, ten years' planning experience).

Of course, RTPI-accredited UK planning programmes encourage students to reflect on how "planning operates within the context of institutional and legal frameworks" (RTPI, 2012, 11). Likewise, there is consideration given to "assessing what can be learnt from experience of spatial planning in different contexts and spatial scales" (RTPI, 2012, 11). Nonetheless, there was also a sense for certain interviewees that paying regard to the legacy of historical and earlier spatial imaginaries might help planners develop a more rounded sense of how places are shaped by global connections, both past and present (Porter and Yiftachel, 2019). Hence there are further opportunities to explore the imprint left by Western planning concepts, which were designed to be woven into networks of rational control, and that sometimes overlooked or suppressed existing indigenous knowledges, affiliations and ways of life (Bhan, 2019; Putri, 2019). For some interviewees, recognising the layered legacy of colonial incursions and the enduring influences of exported Western planning models, remains an important task for educators, students and future planners (cf. Jazeel, 2019;):

What is tricky in terms of global source, global South, global North, is that what I have noticed is that the students them - some of the students from the global South come to us because they think that our planning practices are superior and they need to learn from these practices to bring them back to. So, they themselves haven't really in a way put themselves in the postcolonial mode. Like, actually, you can question some of the stuff you are going to hear because it may be that it's rooted in very colonial or exploitative practices. [So], there is an interesting ambiguous dimension here (R6, female, Russell Group university).

I think because of the academic pressures, academics and literature has got more theoretical. I'm not sure that's an entirely good thing. I think the sort of discourse of planning has got more abstract. But actually to understand the history and the background of your profession 
and where it came from and what it's done in different places, and what the debates have been around the outcomes of planning, is probably a better way of making people wise about future decisions (R10, male, Russell Group university).

Clearly, there is an inevitable danger of somehow romanticising knowledge generated in the global South (Roy, 2011). Not all Southern knowledge can be straightforwardly applied or uncritically accepted in the global North. Likewise, wholesale decolonialisation of planning curricula may not be appropriate, given the different tempos and rhythms of internationalisation being experienced in certain institutions Nevertheless, postcolonial ideas have wider traction too, especially the "lingering effects" (Jazeel, 2019, 5) of earlier Imperial or colonial interventions, and the hybrid identities these create in many urban centres in the West (King, 2009; Roy and Ong, 2011). Acknowledging that legacies of global connection have created diverse urban centres may help broaden current interpretations of change, which stress importance of corporate finance, compliant planners and avaricious developers in shaping urban environments.

Moreover, in thinking of urban communities in a far more dynamic, fluid and contextualised way to understanding the "uprootings" and "re-groundings" associated with the vibrant social networks of the contemporary city. Well-documented fears surrounding a shortage of trained UK planners, combined with ongoing concerns around public sector cutbacks, might place a practical break on such ambitions. Even so, encouraging students to reflect on customs, cultures and forms of exchange that take place in those communities shaped by colonial forces, presents an opportunity for planners to work more closely with diverse groups. For some, this remains an overlooked task for planners when it comes to planning socially-just, well-designed sustainable places (Sandercock and Piazzoni, 2017; Jackson et al., 2018). Or, as one interview suggested:

We encourage students to reflect not just about planning practice are not good or bad in themselves, some systems and approaches are not superior, and some are not inferior, they all have their advantages and inconvenience. But we critically engage with this issue of policy mobilities, [by asking students to question] the dominance of certain models, power relationship, the selling of planning ideas $[. .$.$] and the discussion is on the city statutes and why$ 
and how it came out of progressive struggle between different groups and those with different backgrounds. [So] we use examples that go beyond the North good, South bad, or North planned, South unplanned. [N]ot all of them get it, but we really ask them to engage head on, so we do ask the British students to try to think about these power dynamics and solutions in different communities and question what's informal and illegal in the British planning system (R6, female, Russell Group university).

\section{Conclusion}

There are repeated calls for increasing numbers of globally attuned trained planners to manage urban growth and create high-quality, sustainable places in different parts of the world (Frank, 2018, 131). At the same time, however, concerns also surround whether planning curricula are suitably positioned to provide future practitioners with the skills, knowledge and experience to wrestle with global challenges of the twenty-first century (Sykes et al., 2015; Hoey et al., 2017; Carolini, 2018; Frank, 2018). Therefore, in response to suggestions for studies that chart how internationalisation plays out across planning curricula, this paper provides a hitherto under-explored insight into the experiential dimension of how UK educators and practitioners encounter efforts to internationalise. On the one hand, some respondents recorded positive views about the benefits of promoting international partnerships and strengthening research collaboration. There are examples of curriculum design helping to increase students' preparedness for planning challenges that stretch out across different time-spaces. But, as the data presented here suggest, institutions, departments and courses face a varied set of internal and external pressures, inherent to the extreme diversity of universities, programmes, students and educators; these factors affect the extent to which internationalisation is reflected in UK planning curricula. Clearly, approaches to recruitment, curriculum design, course delivery, teaching and research agendas vary both spatially and temporally. Hence a degree of sensitivity is required before advocating a radical re-positioning of UK planning curricula. But as the narratives unearthed in this paper suggest, there remains a wider, unresolved tension around the balance between providing locally focused, professionally accredited education, and efforts to broaden planning programmes that appeal to lucrative overseas markets. 
Nevertheless, there are several practical suggestions emerging from the data that would certainly help with curriculum delivery and provide planning practitioners with necessary skills to deliver future planning solutions, while contributing to a wider culture of open debate and cosmopolitan thinking (Amin, 2019, 5). As the data reveal, most fundamentally, efforts to internationalise need to be managed, resourced and sustained in ways that benefit staff and students. Further opportunities may emerge for certain institutions to align international marketing, student recruitment and support services with staff expertise, teaching and research agendas. As with other recent research, there are clear messages around the need to build staff expertise, motivations and willingness to embrace opportunities associated with internationalisation (Sykes et al., 2015). That said, this study cleaves open other potentially rich lines of further inquiry relating to the sensate, embodied ways in which staff and students of different backgrounds, encounter official efforts to embed internationalisation across different higher education time-spaces (Holton and Finn, 2018,438 ). Although this research is limited to the UK context, providing further critical reflections on the individual lifeworlds, personal motivations and experiences of staff and (former) students across different university settings (Peel and Frank, 2008, 103 - 105), should help with building inter-institutional dialogue and shared knowledge bases in the future delivery of internationalised planning education (for example, Hoey et al., 2017; Carolini, 2018).

Certain UK planning programmes are incorporating a more relational, comparative set of ideas that push planners to reconsider established Western knowledge bases and teaching practices; this will prime students and future practitioners the necessary skills to work more sensitively in different geographical contexts (for example, Frank and Peel, 2008; Sykes et al., 2015). Connecting theory to practice through the insertion of comparative perspectives and case studies on "housing policy, economic development, disaster planning, environmental planning, food systems planning" or other topics, might indeed expose greater numbers of students to important global dimensions of planning (Hoey et al., 2017, 231). But as the data presented in this paper suggests, weaving more comparative international case studies into planning curricula needs to be fully contextualised in ways that take a fuller account of socio-economic, political, historical and regulatory forces shaping the contemporary planning landscape. Here there is scope to expand the range of 
case studies and teaching resources to include further reflection on the tensions inherent with planning at a time when the world of places, such as nations, cities and regions, replete with borders and controls, are being challenged by the dynamics of an increasingly networked global society.

Expanding the diversity of educational practices remains a challenging task, especially given the continued importance attached to "planning's nationally differentiated professional milieus", where "the international accreditation of nationally and professionally focused programmes is particularly difficult to achieve" (Frank, 2018, 139). Remaining alive to historical currents of planning thought is also important here. Developing historically contextualised understandings of how indigenous populations respond to, modify, or subvert externally imposed planning approaches is also important for those future planners and their efforts to create sustainable places (Porter and Yiftachel, 2019). But this should not be a straightforward exercise that involves endlessly ruminating over the application of traditional planning concepts, theories and narratives developed in the global North. As the interview and survey data reveal, while context matters, postcolonial thought also offer new impetus to professional bodies, institutions, planning educators and students to reflect on the diverse histories and geographies of globalisation. This enables the geographical movement of historical connections which continue to shape cities - in the global South and the global North - to be questioned. Likewise, further consideration could be given to whether different kinds of "tactical urbanism" found in parts of the global South are transferable to other contexts. But there are other opportunities, too, for further exploration of how the collective memories, traditions, customs and sense of place attachment manifest in diasporic communities in parts of the global North clash, evade or align with efforts to remodel or re-purpose urban space. This remains a fundamental marshalling point in arguments for more hopeful planning interventions (Sandercock and Piazzoni, 2017) bolstering planners' ongoing efforts to build stronger, safer, cleaner, welldesigned and sustainable places. 


\section{References}

ALTBACH, P. and DE WIT, H. (2018), 'Are We Facing a Fundamental Challenge to Higher Education Internationalization?', International Higher Education, 93, 2-4.

AUGUR, P. (2019), Independent panel report to the review of post-18 education and funding. Retrieved from https://assets.publishing.service.gov.uk/government/uploads/system/uploads/attac hment_data/file/805127/Review_of_post_18_education_and_funding.pdf

AMIN, A. (2019), 'Editorial: 'Global' Brexit Britain', British Academy Review Spring 2019, 3-7.

BHAN, G. (2019), 'Notes on a Southern urban practice', Environment and Urbanization, 1-16, https://doi.org/10.1177/0956247818815792.

BLATMAN-THOMAS, N. and PORTER, L. (2019), 'Placing property: Theorizing the urban from settler colonial cities', International Journal of Urban and Regional Research, 43, 30 45.

CAROLINI, G. (2018), 'Go South, Young Planner, Go South', Journal of Planning Education and Research, https://doi.org/10.1177/0739456X18754317.

CRAGGS, R. (2019), 'Decolonising The Geographical Tradition', Transactions of the Institute of British Geographers, https://doi.org/10.1111/tran.12295.

DE SATGÉ, R. and WATSON, V. (2018), 'Introduction' in R. de Satgé and V. Watson (eds) Urban Planning in the Global South: Conflicting Rationalities in Contested Urban Space, Palgrave Macmillan, London.

FRANK, A. (2018), 'Adapting, Shifting, Defining New Roles: Education for a Maturing Professional Field', in A. Frank and C Silver (eds), Urban Planning Education: Beginnings, Global Movements and Future Prospects, London, Springer, 131-46.

HAIGH, M. (2014), 'From internationalisation to education for global citizenship: A multilayered history', Higher Education Quarterly, 68, 6-27.

HOEY, L., RUMBACH, A. AND SHAKE, J. (2017), 'Bringing Practice to the Classroom: Using a Deliberative Learning and Case Study Approach to Teach International Planning', Journal of Planning Education and Research, 37, 223-33.

HOLTON, M. and FINN, K. (2018), 'Being-in-motion: the everyday (gendered and classed) embodied mobilities for UK university students who commute', Mobilities, 13, 42640. 
JACKSON, A., GARCIA-ZAMBRANA, I., GREENLEE, A.J., LEE, C.A. and CHRISINGER, B. (2018), 'All Talk No Walk: Student Perceptions on Integration of Diversity and Practice in Planning Programs', Planning Practice \& Research, 33, 574-95.

JAZEEL, T. (2019), Postcolonialism, Routledge, London.

KING, A. (2009), 'Postcolonial cities', in N. Thrift and R. Kitchin (eds), International Encyclopaedia of Human Geography, Amsterdam, Elsevier, 321-26.

KNIGHT, J. and DE WIT, H. (2018), 'Internationalization of higher education: past and future', International Higher Education, 95, 2-4.

KUNZMANN, K. (2019), 'Why not Italian? Differences matter! A comment on Ben Davy's Viewpoint in TPR', Town Planning Review, 90, 3-9.

MADGE, C., RAGHURAM, P. and NOXOLO, P. (2015), 'Conceptualizing international education: From international student to international study', Progress in Human Geography, 39, 681-701.

MILLINGTON, G. (2016), 'The cosmopolitan contradictions of planetary urbanization', The British Journal of Sociology, 67, 476-96.

PEEL, D. and FRANK, A. (2008) 'Planning Education Forum: The internationalisation of planning education: issues, perceptions and priorities for action', Town Planning Review, 79, 87-123.

PORTER, L. and YIFTACHEL, O. (2019), 'Urbanizing settler-colonial studies: introduction to the special issue', Settler Colonial Studies, 9, 177-86.

PUTRI, P.W. (2018), 'Sanitizing Jakarta: decolonizing planning and kampung imaginary', Planning Perspectives, 1-21, https://doi.org/10.1080/02665433.2018.1453861.

RATNAYAKE, R. and BUTT, A. (2018), 'Encounters with the unfamiliar: international planning education', International Planning Studies, 23, 51-64.

ROBINSON, J. (2018), 'The politics of the global urban', in S. Oosterlynck, L. Beeckmans, D. Bassens, B. Derudder, B. Segaert and L. Braeckmans (eds) The City as a Global Political Actor, Routledge, London.

ROY, A. (2011), 'Slumdog cities: rethinking subaltern urbanism', International Journal of Urban and Regional Research, 35, 223-28.

ROY, A. and ONG, A. (2011), Worlding Cities: Asian Experiments and the Art of Being Global, 42, Chichester, John Wiley \& Sons. 
SANDERCOCK, L. and PIAZZONI, M. (2017), 'Interview with Leonie Sandercock', Critical Planning, 23, Retrieved from https://escholarship.org/uc/item/8sd7v4hh.

SIMONE, A. (2010), City Life from Jakarta to Dakar: Movements at the Crossroads, New York, Routledge.

SUNDARAM, R. (2010), Pirate Modernity, Delhi's Media Urbanism, London and Delhi, Routledge.

SYKES, O., JHA-THAKUR, U. and POTTER, K. (2015) “"What's Love Got to Do With It?" Some reflections on the Internationalisation of planning education', Planning Education, 3, 82-91.

THE ROYAL TOWN PLANNING INSTITUTE (2012), 'Policy Statement on Initial Planning Education, revised 2012', Royal Town Planning Institute, London.

UN HABITAT (2009), Global Report on Human Settlements 2009, Planning Sustainable Cities, Earthscan, London.

WARD, S. (1999), 'The international diffusion of planning: a review and a Canadian case study', International Planning Studies, 4, 53-77.

WATERS, J. (2012), 'Geographies of international education: Mobilities and the reproduction of social (dis) advantage', Geography Compass, 6, 123-36. 